mental health status, health behaviours, retrospective sickness absence, overall work ability and negative affectivity.

Discussion Self-report PA instruments are generally known to suffer from poor absolute criterion validity, and fail to capture all relevant PA. This study aims to increase the knowledge of the cardiovascular health of employees in physically demanding jobs with objective measurements.

\section{LAMPLIGHTER PROGRAM - INDIA A SUSTAINABLE MODEL TO ACHIEVE WELLNESS AT THE WORKPLACE (SHARING EXPERIENCES OF A 12 YEAR FOLLOW-UP STUDY)}

${ }^{1}$ Kishore Madhwani, ${ }^{2}$ Hanasoge Ravimohan, ${ }^{3}$ Sudip Gupta, ${ }^{4} \mathrm{~T}$ Rajgopal, ${ }^{5}$ Damodar Lele, ${ }^{5}$ Ranjana Thatte, ${ }^{5}$ Amruta Desai, ${ }^{6}$ Mira Santiago. ${ }^{1}$ Medical and Occupational Health Consultant and Head Western India, Hindustan Unilever Limited, Mumbai, India; ${ }^{2}$ Specialist, MandOH Southern India, Hindustan Unilever Ltd, Bangalore, India; ${ }^{3}$ Area Medical Officer and Head, East and North India, Hindustan Unilever Ltd., Kolkata, India; ${ }^{4}$ Vice Preident Global, Medical and Occupational Health, Unilever, Mumbai, India; ${ }^{5}$ Consultant Medical Officer, Mumbai, India; ${ }^{6}$ Assistant Manager, Medical and Occupational Health, Mumbai, India

\subsection{6/oemed-2018-ICOHabstracts. 185}

Introduction In 2006, Lamplighter Program was globally launched to enhance employee wellbeing, resonating with Unilever's Sustainable Living Plan. From 2014, the Framingham Risk Frame Model is used to focus on employees' vulnerable to cardio-vascular ailments.

Methodology Health Status of employees is measured by calculation of Vitality Index* (VI), comprising 4 parameters (Blood Pressure, BMI, Serum Cholesterol and Glucose).A baseline evaluation in 2006 resulted in $88 \%$ participation $(n=14,233)$. Based on values of parameters, VI* Scorecard was prepared for each employee ensuring confidentiality. Employees with score 0-4 were designated Greens, 5-6 Ambers and $7+$ as Reds. Since 2007, VI* is calculated during pre - employment and periodic check-ups. Subsequently, reds and ambers are closely followed-up every year (by a prospective study) to ensure reduction in risk factors by combination of lifestyle changes, treatment and specialist consultations. In 2014, Framingham Risk Model was introduced, taking into consideration lipid profile, personal history of smoking, aerobic activity,family history of heart disease, hypertension and cancer.

Results While VI* focussed primarily on health promotion, introduction of Framingham Risk Model helped in specific protection of the high risk group, as our earlier risk assessment model did not assess risk of coronary artery disease, age, gender, smoking history and family history of heart disease. This has helped us in bringing another 9.1\% participant employees' under rigorous monitoring in 2015, and $8.3 \%$ in 2016. Baseline evaluation in 2006 revealed $75 \%$ employees were green, 17\% amber and 8\% reds. Follow-up from 2007 to 2016 (78\% participation) revealed that number of reds over the years reduced to $6.6 \%$, ambers to $14.9 \%$ and greens increased to $78.5 \%$.

Discussion Along with calculation of $\mathrm{VI}^{*}$, inclusion of Framingham Risk Frame Model is an excellent tool to focus on employees requiring further interventions. The Health Care Model at Hindustan Unilever Limited combines element of caring for an employee while making it sustainable from a business perspective.

\section{7 ARTERIAL HYPERTENSION RISK IN A WORKING POPULATION}

1,2Manfredi Montalti* ${ }^{1}$ Antonio Zanobini, ${ }^{1}$ Enrico Luchetti, ${ }^{2}$ Giulio Arcangeli. ${ }^{1}$ Occupational Medical service soc. coop, Pistoia Italy; ${ }^{2}$ ccupational medicine department Università di Firenze, Firenze, Italia

\subsection{6/oemed-2018-ICOHabstracts. 186}

Introduction During last years the life expectation and working duration is increasing and consequently is more frequent visiting during periodical medical surveillance workers affected to chronic illness connected to ageing. Arterial hypertension is an age related medical condition that represent an important risk factor for illness potentially impacting on fitness to work. And also can be worsted by some occupational risk as noise, physical load and mental stress.

Methods We analysed 8628 (3159 females and 5468 males) medical report collected during periodical medical surveillance. Average age were 42,6 years $\pm 11,3$ (males 42,8 years $\pm 11,1$, females 42,2 years $\pm 11,3$ ) and average BMI were of $24,9 \mathrm{Kg}$ / $\mathrm{m}^{2}$ (males 25,8, females 23,5). We consider a worker affected by arterial hypertension when systolic blood pressure is over $140 \mathrm{mmHg}$ or diastolic pressure is more than $90 \mathrm{mmHg}$ or in case he takes antihypertensive therapy.

Result Workers affected to arterial hypertension were 1756, $20,3 \%$ of workers (498 females, $15,7 \%$ and 1258 males, $23 \%$ ) with an average age were 49,7 years (males 49,1, females 51,1 years) and average BMI were of $27,5 \mathrm{Kg} / \mathrm{m}^{2}$ (males 27,8, females 24,7). These workers resulted totally fit to work were $85,0 \%$, ones with limitations in their fit to work were $14,4 \%$, and only $0,6 \%$ were unfit to work. About occupational activities we found the higher percentage of workers with arterial hypertension in drivers were $35,6 \%$ (mean age 44,3 and average BMI 26,6) and in construction workers $30,3 \%$ (mean age 44,3 and average BMI 26,6) vs i.e. $17,4 \%$ of office workers (mean age 42,6 and average BMI 23,9).

Discussion Our analysis confirms the importance of company strategies to promote health promotion at work considering the progressive worker's ageing. In accord with our data the intervention for reducing cardiovascular risk factor is more urgent in some occupational group as drivers and construction workers.

\section{Communications in Occupational Health}

\section{ADVOCACY TRAINING TO ACHIEVE POSITIVE NATIONAL POLICY CHANGE IN OCCUPATIONAL HEALTH}

NJ Pahl. Society of Occupational Medicine, London, UK

\subsection{6/oemed-2018-ICOHabstracts. 187}

How can Government policy in occupational health and medicine be changed for the better?

Advocacy is a process which can lead to change through influence. It is a way of influencing public policy through information and communication, directing decision-makers towards a solution and can be used to inform influential groups and raise their awareness of specific issues. Advocacy in occupational health can achieve:

- Increased resources for occupational health- building the case where it is not yet recognised 